\title{
Risk factors of peripheral neuropathy in patients with type 2 diabetes in Isfahan: Results of a cohort study in Iran
}

\author{
Abdollah Mohammadian-Hafshejani ${ }^{1}$, Reza Majdzadeh ${ }^{2}$, Nasrin Mansournia ${ }^{3}$, Mohammad Ali Mansournia ${ }^{4, *}$
}

${ }^{1}$ Department of Epidemiology and Biostatistics, School of Public Health, Tehran University of Medical Sciences, Tehran, Iran

${ }^{2}$ Professor of Epidemiology, Department of Epidemiology and Biostatistics, School of Public Health, Tehran University of Medical Sciences, Tehran, Iran

${ }^{3}$ Associate Professor of Endocrinology and Metabolism, Department of Endocrinology, AJA University of Medical Sciences, Tehran, Iran

${ }^{4}$ Associate Professor of Epidemiology, Department of Epidemiology and Biostatistics, School of Public Health, Tehran University of Medical Sciences, Tehran, Iran

\section{Correspondence}

Mohammad Ali Mansournia, Associate Professor of Epidemiology, Department of Epidemiology and Biostatistics,

School of Public Health, Tehran

University of Medical Sciences, Tehran, Iran

Email: amohamadii1361@gmail.com History

- Received: Oct 19, 2018

- Accepted: Nov 17, 2018

- Published: Dec 29, 2018

DOI :

https://doi.org/10.15419/bmrat.v5i12.512

\section{Check for updates}

Copyright

(c) Biomedpress. This is an openaccess article distributed under the terms of the Creative Commons Attribution 4.0 International license.

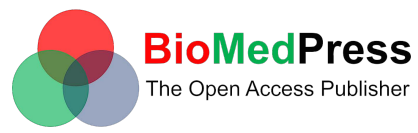

\begin{abstract}
Introduction: Peripheral neuropathy (PN) is among the most prevalent complications of diabetes that can lead to impairment of mobility of diabetic patients. The purpose of the current study was to predict relative factors influencing the occurrence of peripheral neuropathy (PN) in patients with type 2 diabetes.Methods: This was a cohort study on diabetic patients in the Isfahan Province of Iran. The studied population consisted of patients with type 2 diabetes, of ages 18 or older, who were diagnosed as new cases of diabetes from 2007 to 2014, and whose follow-up was completed by the end of 2016. In this study, with regards to the presence of time-varying co-variates, timedependent Cox regression model was employed in order to estimate the Hazard Ratio (HR) of PN in the diabetic patients. Results: Overall, 1874 patients with diabetes participated in the study, of which 839 (44.77\%) were men and 1035 (55.23\%) were women. During the study period, PN occurred in $17.98 \%$ of the patients; the ratio was $17 \%$ in women and $19.18 \%$ in men. In comparison to the reference group, the adjusted HR of PN in males was equal to 3.66 (95\% Cl: 1.15-11.67), in housewives was equal to 4.09 (95\% Cl: 1.02-16.38), and divorced or wife died patients was equal to 3.02 (95\% Cl: 1.61-5.65). In addition, for each 6 month follow-up of the patients, the adjusted HR of PN increased to 1.19 (95\% Cl: 1.17-1.22). Conclusions: The adjusted HR of PN in men, in housewives, and elderly people, divorced or wife died patients, with elementary education level were greater than the reference group. Thus, training, screening and diagnostic programs should be carried out with greater sensitivity in patients who are at greater risk for PN.

Key words: Cohort study, Peripheral neuropathy, Risk factors, Time dependent Cox regression model, Type 2 diabetes
\end{abstract}

\section{INTRODUCTION}

Diabetes includes a group of metabolic disorders that is associated with high blood glucose levels and impaired carbohydrate, lipid and protein metabolism. It is a disease that results from a disorder in the function or secretion of insulin. The two common groups of diabetes are known as type 1 (diabetes dependent on insulin) and type 2 (diabetes not dependent on insulin $)^{1}$. According to the existing estimates, in 2011 more than 366 million people all over the world had diabetes and this number will increase up to $522 \mathrm{mil}-$ lion people by $2030^{2}$.

Peripheral neuropathy $(\mathrm{PN})$ is among the most prevalent complications of diabetes that can lead to impaired mobility of patients with diabetes ${ }^{2,3}$. The prevalence of $\mathrm{PN}$ is different in numerous studies and also differs from country to country; the prevalence has been reported to be between 1.5 to $80 \%{ }^{4-8}$. PN involves about $37 \%$ of patients with type 1 diabetes, and at least $20-40 \%$ of patients with type 2 diabetes ${ }^{9}$. The prevalence of PN was equivalent to $34 \%$ in the study carried out by Nitiyanant et al. that evaluated the control of diabetes across 230 diabetes care centers in 12 Asian countries ${ }^{10}$. In a review study, which used the meta-analysis method to assess the results of
21 studies conducted in Iran from 1991 to 2013, the prevalence of diabetic-associated $\mathrm{PN}$ was estimated to be about $53 \%$. Therefore, based on the results of that study, it can be stated that the prevalence of PN in Iranian patients is high; as such, more than half of the patients with diabetes have $\mathrm{PN}^{11}$.

In the European Diabetes (EURODIAB) Prospective Complications Study, in which 1172 patients were followed for 7 years, the cumulative incidence rate of PN was equivalent to $23.5 \%{ }^{12}$. According to the results of that study, the risk of having PN was related to the level of glycated hemoglobin (HBA1c) and the duration of diabetes ${ }^{13}$. Moreover, in the Pittsburgh Epidemiology of Diabetes Complications (EDC) Study, it was observed that the cumulative incidence of $\mathrm{PN}$ after 4-year follow-up of the diabetic patients was about $13 \%{ }^{13}$ and after 10 years of follow up, it increased up to $34.2 \%{ }^{14}$

Therefore, in light of the high prevalence of type 2 diabetes and importance of $\mathrm{PN}$ in diabetic patients and that, thus far, limited studies have been conducted to determine the factors affecting the occurrence of PN in patients with diabetes in Iran, this current study was conducted with the aim of examining the incidence rate and factors of PN occurrence in patients with type 2 diabetes in Isfahan, Iran. The results of this 
study could help to identify the people most at risk for $\mathrm{PN}$ in order to accelerate initiation of effective diagnostic and therapeutic interventions. This should decrease the incidence of $\mathrm{PN}$ in diabetic patients, as well as improve the quality of life and survival of these patients.

\section{METHODS}

\section{Research design and data source}

This is a cohort study on diabetic patients living in the Isfahan province of Iran. After the diagnosis of diabetes, a file called "diabetic's file" was created for each diabetic in the Diabetic Patient Care Program in the healthcare system of Iran. In this study, data of the assessed variables were extracted by the researcher from the diabetic patient's records. For time-varying variables, collection of data was conducted through repeated measurements at a time interval of 6 months until the end of the follow-up period. Furthermore, the information about occurrence of PN was extracted from the patient's files and referral forms to specialists.

\section{Study population}

The study population consisted of patients with type 2 diabetes mellitus (ages 18 or older) who were diagnosed as new cases of diabetes from 2007-2014 and who were registered in diabetes files of health centers, health houses, and diabetes clinics. These patients received regular health care (at least once every 180 days) for a minimum of 2 years. Patient follow-up was done by the end of 2016 .

\section{Inclusion criteria of the study}

1. Patients with type 2 diabetes mellitus, of ages 18 or older.

2. Newly diagnosed patients from $2007-2014$ as a new case of diabetes.

3. Patients registered in diabetes files of health centers, health houses, and diabetes clinics, and who were referred regularly to receive health care services.

4. Patients residing in the Isfahan province (of Iran).

\section{Exclusion criteria of study}

1. Dialysis patients

2. Patients who did not regularly follow clinical and laboratory examinations for at least once every 6 months.
Censored patients in the research were as follows

1. Patients who missed the follow-up period.

2. Patients with no regular treatment.

3. Cases with no study outcomes until the end of the follow-up period.

\section{Study variables}

Time-varying variables or time-dependent variables included: Glycated hemoglobin (HbA1C), Fasting blood sugar (FBS), Body Mass Index (BMI), Systolic Blood Pressure (SBP), Diastolic Blood Pressure (DBP), and type of diabetes treatment.

Basic variables of this study were as follows: Gender, residential place, occupation, educational level, marital status, smoking status, age, physical activity level (PAL), receiving aspirin, high-density lipoprotein (HDL), low-density lipoprotein (LDL), triglyceride, cholesterol, lipid-lowering drugs, and basic values of time-varying variables.

The properties of the data collection tool and collection method: The data analyzed in the present study (demographics, clinical and para-clinical information of patients, etc.) were gathered by using a researchermade checklist with the aid of the information from the files of families and/or the diabetes files of patients, or by phone calls with patients if the required information were not sufficient. Follow-up of patients continued until the end of study and/or occurrence of PN.

\section{Peripheral neuropathy diagnosis}

In the current study, the diagnosis of PN was carried out by a trained doctor, the Michigan questionnaire, and the monofilament test. Some information about the signs of $\mathrm{PN}$ in the diabetic patients, as well as the nail and skin conditions, were investigated via the Michigan questionnaire. In the Michigan questionnaire, 4 factors were addressed, namely the outer appearance of the foot skin (in terms of the skin's dryness or cracked skin, callus, infection, and/or deformity of body), existence of ulcer, reflex of Achilles Tendon, and situation of vibration feeling. The factors were assessed by utilizing 128 hertz diapason in the toe, and a score bigger than 2 was considered as $\mathrm{PN}$ existence $^{15}$. In terms of PN, the ten-point monofilament test was performed in ten parts of the sole and back of the leg; the lack of monofilament at one or more points indicated $\mathrm{PN}^{16}$.

\section{Data analysis}

In this study, use was made of the statistical chisquare test in order to assess the relations of qualitative variables. An independent t-test was employed to compare the means of quantitative variables in patients with $\mathrm{PN}$ versus patients without $\mathrm{PN}$, as well among men and women. In this study, with regards 
to the presence of time-varying co-variates, the timedependent Cox regression method was employed in order to estimate the Hazard Ratio (HR) of PN in diabetic patients. The adjusted HR for any variable was adjusted for all other variables. The HR was calculated by considering the $95 \%$ confidence interval (CI). The significance level in all tests was considered as $5 \%$. The statistical software SPSS 18 and Stata 15 were used for analysis of data.

\section{RESULTS}

Overall, 1874 patients with type 2 diabetes participated in the study. Of this total, $839(44.77 \%)$ of the patients were men and 1035 (55.23\%) were women. The average age of the study patients was $56.47 \pm$ 15.69; it was $57.57 \pm 15.19$ in men and $55.57 \pm$ 16.04 in women $(p=0.006$; this difference was significant). The average age of the diabetic patients with PN symptoms was equivalent to $59.46 \pm 15.13$ years and in patients without PN was equivalent to $53.55 \pm 15.38$ years; this difference was statistically significant $(\mathrm{p}=0.004)$. During the study period, PN occurred in $17.98 \%$ of the patients; from this proportion, $17 \%$ were women and $19.18 \%$ were men. The demographic, clinical and para-clinical properties of the study patients are observable in Tables 1, 2 and 3. In comparing the average of quantitative variables between patients with $\mathrm{PN}$ and those without $\mathrm{PN}$, it was observed that the patients with $\mathrm{PN}$ are older $(\mathrm{p} \leq 0.001)$ and have higher BMI $(\mathrm{p}=0.139)$, FBS $(\mathrm{p} \leq 0.001)$, HBA1c $(\mathrm{p} \leq 0.001)$, Cholesterol $(\mathrm{p}=0.065)$, LDL $(\mathrm{p}=0.068)$, SBP $(\mathrm{p}=0.001)$, and DBP $(\mathrm{p}=0.001)$, compared to patients without PN (Tables 2 and 3 ).

The incidence rates of $\mathrm{PN}$ in each 1000 person-year follow-up for the following groups were as follows: in men it was 37.91 (95\% CI: 32.49-44.25), in women it was 34.61 (95\% CI: 29.85-40.12), in urban patients it was 36.91 (95\% CI:29.73-45.83), in rural patients it was 35.86 (95\% CI:31.72-40.54), in diabetic patients with oral medicine regimen it was 34.38 (95\% CI:30.44-38.83), in patients with oral medicines and insulin therapeutic regime, the incidence rate was 43.35 (95\% CI:34.72-54.13), in patients with normal BMI it was 31.87 (95\% CI:26.28-38.67), in overweight patients it was 38.24 (95\% CI:32.60-44.85), in obese patients it was 38.56 (95\% CI:31.10-47.83), in patients with low physical activity it was 37.47 (95\% CI:33.1342.37), in patients with moderate physical activity it was 32.12 (95\% CI:24.99-41.28), in patients with high physical activity it was 32.58 (95\% CI:18.91-56.10), and in patients with very high physical activity the incidence rate was equivalent to 35.29 (95\% CI:18.3667.83). The incidence rates based on all the studied variables are shown in Table 4.

In comparison to the reference group, the un-adjusted $\mathrm{HR}$ of $\mathrm{PN}$ in rural patients was equal to 0.96 (95\% CI: 0.75-1.23), in men it was 1.09(95\% CI: 0.88-1.35), in illiterate patients it was 3.02(95\% CI: 1.71-5.32), in patients with elementary education it was $2.64(95 \%$
CI: 1.48-4.71), in patients with junior school education it was 2.11(95\% CI:1.12-3.98), in patients with high school education it was 2.16(95\% CI: 1.15-4.03), in retired patients it was $1.95(95 \%$ CI: $0.83-4.55)$, in housewives it was 1.83 (95\% CI: 0.86-3.90), in unemployed patients it was 2.42(95\% CI: 1.11-5.29), in patients receiving blood anti-lipid drugs it was 1.28(95\% CI: 1.03-1.64), in people receiving oral medicines and insulin for diabetes therapy it was $1.29(95 \%$ CI: 1.021.66 ), and in patients receiving aspirin it was equal 1.43(95\% CI: 1.10-1.86). Moreover, the un-adjusted $\mathrm{HR}$ of $\mathrm{PN}$ for one-unit increase in BMI was equal to 1.019 (95\% CI:0.995-1.044), for the FBS it was 1.02(95\% CI: 1.01-1.03), for HBA1c it was $1.10(95 \%$ CI: 1.04-1.16), for LDL it was $1.002(95 \%$ CI: 0.999 1.005), for HDL it was 0.999(95\% CI: 0.989-1.008), for SBP it was 1.014(95\% CI: 1.006-1.023), and for DBP it was 1.016(95\% CI: 1.007-1.026). The un-adjusted HR based on the other studied variables are observable in Table 5.

In comparison to the reference group, the adjusted HR of PN in males was equal 3.66 (95\% CI:1.1511.67), in housewives it was 4.09 (95\% CI: 1.02-16.38), in unemployed patients it was 2.08 (95\% CI: $0.93-$ 4.67), in retired patients it was 1.65 (95\% CI: 0.69 3.94 ), in self-employment patients was equal to 1.56 (95\% CI: 0.71-3.43), in married patients was equal to 2.18 (95\% CI: 1.24-3.83), and in divorced or wife died patients was equal to 3.02 (95\% CI: 1.61-5.65). In addition, by increasing the follow-up of patients, the HR of PN increased such that in each 6-month follow-up, the adjusted HR of PN increased to 1.19 (95\% CI:1.171.22) Table 6.

\section{DISCUSSION}

The current study examined the incidence rate and the factors influencing $\mathrm{PN}$ occurrence in patients with type 2 diabetes in Isfahan, Iran. During the study period, $\mathrm{PN}$ occurred in $17.98 \%$ of the patients. This proportion in women is $17 \%$ and in men is $19.18 \%$. The incidence rates of $\mathrm{PN}$ in men, urban patients, people on oral medication and insulin therapeutic regimen, people who were overweight and/or obese, and people with low physical activity were higher than the other groups. In the multivariate time-dependent Cox regression model, it was observed that in comparison to the reference group, the HR of PN in men, housewives, divorced or wife died patients, and people with high school education level were much greater.

In a study conducted with Marvasti et al. in Isfahan, the cumulative incidence of PN during a 10-year follow-up was equivalent to $30.7 \%$, and in other study (by Tesfaye et al.) the cumulative incidence of PN during a 7 -year follow-up was equal to $23.5 \%{ }^{12}$. In a study carried out by Lioyd et al. with 4 years of follow-up, the incidence of PN was $13 \%$, and after a 10 -year follow-up it was $34.2 \%{ }^{13}$. Similarly, in a study by Sands et al., after 5 -year follow-up of patients it was $28.6 \%{ }^{17}$. 
Table 1: Demographic, clinical and paraclinical characteristics of the studied patients

\begin{tabular}{|c|c|}
\hline Variables & Total \\
\hline \multicolumn{2}{|l|}{ Residential place } \\
\hline Rural & $1417(75.62)$ \\
\hline Urban & $457(24.38)$ \\
\hline \multicolumn{2}{|l|}{ Gender } \\
\hline Male & $839(44.77)$ \\
\hline Female & $1035(55.23)$ \\
\hline \multicolumn{2}{|l|}{ Educational level } \\
\hline Illiterate & $751(40.07)$ \\
\hline Elementary school (one to five years learning) & $470(25.08)$ \\
\hline Junior school (six to nine years learning) & $197(10.51)$ \\
\hline High school (ten to twelve years learning) & $234(12.48)$ \\
\hline Academic education & $222(11.84)$ \\
\hline \multicolumn{2}{|l|}{ Occupation } \\
\hline Governmental & $54(2.88)$ \\
\hline Self-employment & $458(24.43)$ \\
\hline Housewife & $931(49.70)$ \\
\hline Unemployed & $288(15.36)$ \\
\hline Retired & $143(7.63)$ \\
\hline \multicolumn{2}{|l|}{ Marital status } \\
\hline Married & 1295(69.10) \\
\hline Single & $306(16.32)$ \\
\hline Divorced or widow & $273(14.56)$ \\
\hline \multicolumn{2}{|l|}{ Smoking status } \\
\hline smoker & $182(9.71)$ \\
\hline Non-smoker & 1692(90.29) \\
\hline \multicolumn{2}{|l|}{ Physical activity level } \\
\hline Low & $1379(73.58)$ \\
\hline Moderate & $369(19.69)$ \\
\hline High & $72(3.84)$ \\
\hline Very high & $54(2.88)$ \\
\hline \multicolumn{2}{|l|}{ Lipid-lowering drugs } \\
\hline No & $1526(81.43)$ \\
\hline Yes & $348(18.56)$ \\
\hline \multicolumn{2}{|l|}{ Type of diabetes treatment } \\
\hline Oral medicines & $1609(85.85)$ \\
\hline Oral medicines and insulin & $265(14.15)$ \\
\hline \multicolumn{2}{|l|}{ Receiving aspirin } \\
\hline No & $1549(82.65)$ \\
\hline Yes & $325(17.35)$ \\
\hline
\end{tabular}


Table 2: Association between PN and demographic, clinical, and paraclinical characteristics of the studied patients

\begin{tabular}{|c|c|c|c|c|}
\hline Variables & Patients without PN & Patients with PN & P-value & Total \\
\hline \multicolumn{5}{|l|}{ Residential place } \\
\hline Rural & 13983(98.2) & $255(1.8)$ & 0.797 & $14238(100)$ \\
\hline Urban & $4351(98.2)$ & $82(1.8)$ & & $4433(100)$ \\
\hline \multicolumn{5}{|l|}{ Gender } \\
\hline Male & $8301(98.1)$ & $161(1.9)$ & 0.361 & $8462(100)$ \\
\hline Female & 10023(98.3) & $176(1.7)$ & & $10199(100)$ \\
\hline \multicolumn{5}{|l|}{ Educational level } \\
\hline Illiterate & $6692(97.8)$ & $150(2.2)$ & 0.001 & $6842(100)$ \\
\hline $\begin{array}{l}\text { Elementary school (one to } \\
\text { five years learning) }\end{array}$ & 4990(98.1) & $97(1.9)$ & & $5087(100)$ \\
\hline $\begin{array}{l}\text { Junior school (six to nine } \\
\text { years learning) }\end{array}$ & 2293(98.5) & $36(1.5)$ & & $2329(100)$ \\
\hline $\begin{array}{l}\text { High school (ten to twelve } \\
\text { years learning) }\end{array}$ & 2566(98.4) & $41(1.6)$ & & $2607(100)$ \\
\hline Academic education & 1793(99.3) & $13(0.7)$ & & $1806(100)$ \\
\hline \multicolumn{5}{|l|}{ Occupation } \\
\hline Governmental & 691(99) & $7(1)$ & 0.032 & $698(100)$ \\
\hline Self-employment & $4648(98.5)$ & $71(1.5)$ & & $4719(100)$ \\
\hline Housewife & 9292(98.2) & $173(1.8)$ & & $9465(100)$ \\
\hline Unemployed & $2547(97.6)$ & $63(2.4)$ & & $2610(100)$ \\
\hline Retired & 1156(98) & $23(2)$ & & $1158(100)$ \\
\hline Marital status & & & 0.001 & \\
\hline Married & 13568(98.2) & $255(1.8)$ & & $13823(100)$ \\
\hline Single & 2571(99.4) & $15(0.6)$ & & $2586(100)$ \\
\hline Divorced or widow & 2195(7) & $67(3)$ & & $2262(100)$ \\
\hline \multicolumn{5}{|l|}{ Smoking status } \\
\hline Smoker & $1848(97.8)$ & $41(2.2)$ & 0.208 & $1889(100)$ \\
\hline Non-smoker & $16486(98.2)$ & $296(1.8)$ & & $16782(100)$ \\
\hline \multicolumn{5}{|l|}{ Physical activity level } \\
\hline Low & $13305(98.1)$ & $254(1.9)$ & 0.720 & $13559(100)$ \\
\hline Moderate & $3725(98.4)$ & $61(1.6)$ & & $3786(100)$ \\
\hline High & $790(98.4)$ & $13(1.6)$ & & $803(100)$ \\
\hline Very high & $514(98.3)$ & $9(1.7)$ & & $523(100)$ \\
\hline \multicolumn{5}{|l|}{ Lipid-lowering drugs } \\
\hline No & 14596(98.3) & $253(1.7)$ & 0.024 & $14849(100)$ \\
\hline Yes & $3738(97.8)$ & $84(2.2)$ & & $3822(100)$ \\
\hline \multicolumn{5}{|l|}{ Type of diabetes treatment } \\
\hline Oral medicines & 14924(98.3) & $259(1.7)$ & 0.038 & $15183(100)$ \\
\hline Oral medicines and insulin & $3410(97.8)$ & $78(2.2)$ & & $3488(100)$ \\
\hline \multicolumn{5}{|l|}{ Receiving aspirin } \\
\hline No & 15388(98.3) & $264(1.7)$ & 0.006 & $15652(100)$ \\
\hline Yes & 2946(97.6) & $73(2.4)$ & & $3019(100)$ \\
\hline
\end{tabular}




\begin{tabular}{|c|c|c|c|c|}
\hline Variable & $\begin{array}{l}\text { The patients with } \\
\text { peripheral neu- } \\
\text { ropathy }\end{array}$ & $\begin{array}{l}\text { The patients without pe- } \\
\text { ripheral neuropathy }\end{array}$ & P-value & All patients \\
\hline Age & $59.46 \pm 15.13$ & $53.55 \pm 15.38$ & 0.001 & $56.47 \pm 15.69$ \\
\hline $\begin{array}{l}\text { Body mass index } \\
\text { (BMI) }\end{array}$ & $27.24 \pm 4.25$ & $26.89 \pm 4.32$ & 0.139 & $26.48 \pm 4.29$ \\
\hline $\begin{array}{l}\text { Fast blood glucose } \\
\text { (FBS) }\end{array}$ & $225.12 \pm 48.6$ & $202.41 \pm 39.82$ & 0.001 & $206.22 \pm 43.11$ \\
\hline $\begin{array}{l}\text { Glycosylated } \\
\text { hemoglobin } \\
\text { (HBAlc) }\end{array}$ & $10.55 \pm 1.78$ & $9.17 \pm 1.59$ & 0.001 & $9.77 \pm 1.65$ \\
\hline Cholesterol & $212.30 \pm 45.23$ & $207.69 \pm 45.42$ & 0.065 & $209.61 \pm 46.12$ \\
\hline $\begin{array}{l}\text { Low density lipopro- } \\
\text { tein (LDL) }\end{array}$ & $132.52 \pm 35.39$ & $128.77 \pm 37.46$ & 0.068 & $131.14 \pm 38.48$ \\
\hline $\begin{array}{l}\text { High density } \\
\text { lipoprotein (HDL) }\end{array}$ & $43.70 \pm 10.68$ & $43.81 \pm 11.42$ & 0.875 & $44.31 \pm 11.82$ \\
\hline $\begin{array}{l}\text { Systolic blood pres- } \\
\text { sure (SBP) }\end{array}$ & $133.80 \pm 12.20$ & $131.47 \pm 12$ & 0.001 & $127.11 \pm 11.19$ \\
\hline $\begin{array}{l}\text { Diastolic blood pres- } \\
\text { sure (DBP) }\end{array}$ & $85.14 \pm 11.17$ & $83.11 \pm 10.63$ & 0.001 & $79.25 \pm 8.50$ \\
\hline
\end{tabular}

In the current study, it was observed that the average age in the diabetic patients who developed PN was 6 years greater than those patients without PN development. Moreover, for each year of increase in age of patients, the HR occurrence of PN will increase by $2 \%{ }^{18}$. In other studies carried out around the world, the same results were obtained. In a study by Barbosa et al. on the patients with PN in Portugal, it was observed that on average, the mean age of patients with $\mathrm{PN}$ was 5.7 years greater than those patients without $\mathrm{PN}^{19}$. Therefore, by raising the age, the risk of $\mathrm{PN}$ is increased in diabetic patients.

Moreover, in the current study, the adjusted HR of the $\mathrm{PN}$ in men was equal to 3.66 (95\% CI: 1.15-11.67). In a study by Booya et al. with the purpose of examining the factors affecting the incidence of diabeticassociated $\mathrm{PN}$, the adjusted odds ratio of $\mathrm{PN}$ in men was equal to $2.9^{18}$. These results are consistent with the findings of the DCCT study (diabetes control and complications trial study $)^{20}$. However, in some studies, the female gender was introduced as the predictive factor for incidence of $\mathrm{PN}$ in diabetic patients ${ }^{21,22}$. Nonetheless, in some studies, no significant statistical relation was observed between gender and risk of developing $\mathrm{PN}^{23,24}$.

In the present study, it was also observed that the type of diabetes treatment affects the occurrence of $\mathrm{PN}$. The incidence rate of $\mathrm{PN}$ in patients who simultaneously received oral medicines and insulin therapeutic regimen was greater than those in other groups; therefore, in comparison to the oral treatment group, the un-adjusted HR of PN was equal to 1.29 (95\% CI: 1.02-1.66). In a study by Marvasti et al., it was observed that compared to the oral treatment group, the
$\mathrm{HR}$ of PN in the insulin-treated group was equal to 1.42 and in the group of insulin and oral treatment, it was equal to $1.41^{25}$.

In the present study, it was observed that increasing the follow-up duration of the Type 2 diabetes patients led to an increase in the HR of PN occurrence. Such results were observed in other studies ${ }^{23,24,26}$. In a study by Booya et al, it was observed that for each 1-year increase of patient follow-up period, the HR of PN occurrence will increase by $10 \%^{18}$. Nonetheless, in some studies, no significant statistical relations were observed between the duration of diabetes and incidence of $\mathrm{PN}^{27,28}$.

Furthermore, in our study, it was observed that the average of HBA1c in patients with $\mathrm{PN}$ was equal to $10.55 \%$ and in patients without the symptoms of $\mathrm{PN}$, it was $9.17 \%$; this difference was statistically significant ( $p \leq 0.001)$. Moreover, the un-adjusted HR of PN increased $10 \%$ per one percent increase in HBA1c. The relation between HBA $1 \mathrm{c}$ and complications of Macrovascular (Heart disease)-related diabetes, and Microvascular diabetes (including peripheral neuropathy, retinopathy, and nephropathy) have been demonstrated in numerous studies ${ }^{29,30}$. In the prospective study in Britain in which the diabetes patients were followed up for an average of 10 years, it was observed that per $1 \%$ increase in level of HBA1c, the complications of diabetes increased by $37 \%{ }^{31}$. In this study, no significant statistical relation was observed between smoking, hypertension and hyperlipidemia, and development of peripheral neuropathy; similar results were observed in the study by Booya et $^{18}{ }^{18}$.

There were some limitations, including the time when there was no record or the information was incomplete regarding some medical cases, in which case 
Table 4: The incidence rate of PN based on the demographic, clinical and Paraclinical characteristics of the studied patients

\begin{tabular}{|c|c|c|c|c|}
\hline Variables & Number of PN & $\begin{array}{l}\text { Follow up(per } \\
\text { person-years) }\end{array}$ & 1000 & $\begin{array}{l}\text { Incidence rate( } 95 \% \text { Confi- } \\
\text { dence interval) }\end{array}$ \\
\hline \multicolumn{5}{|l|}{ Gender } \\
\hline Male & 161 & 4.2462 & & $37.91(32.49-44.25)$ \\
\hline Female & 176 & 5.0852 & & $34.61(29.85-40.12)$ \\
\hline \multicolumn{5}{|l|}{ Residential place } \\
\hline Urban & 82 & 2.2211 & & $36.91(29.73-45.83)$ \\
\hline Rural & 255 & 7.1102 & & $35.86(31.72-40.54)$ \\
\hline \multicolumn{5}{|l|}{ Age } \\
\hline 43 and lower & 58 & 2.5547 & & $22.70(17.55-29.36)$ \\
\hline $44-55$ & 69 & 2.3060 & & $29.92(23.63-37.88)$ \\
\hline $56-67$ & 82 & 2.4595 & & $33.34(26.85-41.39)$ \\
\hline 67 and higher & 128 & 2.0111 & & $63.64(53.52-75.68)$ \\
\hline \multicolumn{5}{|l|}{ Occupation } \\
\hline Retired & 23 & 0.5965 & & $38.56(25.62-58.02)$ \\
\hline Government job & 7 & 0.3541 & & $19.76(9.42-41.46)$ \\
\hline Non-government job & 71 & 2.3634 & & $30.04(23.80-37.90)$ \\
\hline Housewife & 173 & 4.7123 & & $36.71(31.62-42.61)$ \\
\hline Unemployed & 63 & 1.3051 & & $48.27(37.71-61.79)$ \\
\hline \multicolumn{5}{|l|}{ Educational level } \\
\hline Illiterate & 150 & 3.4279 & & $43.75(37.28-51.35)$ \\
\hline Elementary school & 97 & 2.5271 & & $38.38(31.45-46.83)$ \\
\hline Junior school & 36 & 1.1739 & & $30.66(22.12-42.51)$ \\
\hline High school & 41 & 1.3042 & & $31.43(23.14-42.69)$ \\
\hline Academic education & 13 & 0.8983 & & $14.47(8.40-24.92)$ \\
\hline \multicolumn{5}{|l|}{ Marital status } \\
\hline Single & 15 & 1.2834 & & $11.68(7.014-19.38)$ \\
\hline Married & 255 & 6.9149 & & $36.87(32.61-41.69)$ \\
\hline Divorced \& Wife died & 67 & 1.1330 & & $59.13(46.54-75.13)$ \\
\hline \multicolumn{5}{|l|}{ Smoking status } \\
\hline Non-smoker & 296 & 8.3742 & & $35.34(31.54-39.61)$ \\
\hline Smoker & 41 & 0.9572 & & $42.83(31.53-58.17)$ \\
\hline \multicolumn{5}{|l|}{ Diabetes therapy } \\
\hline Oral medicines & 259 & 7.5324 & & $34.38(30.44-38.83)$ \\
\hline Oral medicines and insulin & 78 & 1.7989 & & $43.35(34.72-54.13)$ \\
\hline \multicolumn{5}{|l|}{ Physical activity } \\
\hline Low & 254 & 6.7783 & & $37.47(33.13-42.37)$ \\
\hline Moderate & 61 & 1.8990 & & $32.12(24.99-41.28)$ \\
\hline High & 13 & 0.3990 & & $32.58(18.91-56.10)$ \\
\hline Very high & 9 & 0.2550 & & $35.29(18.36-67.83)$ \\
\hline \multicolumn{5}{|l|}{ BMI } \\
\hline Normal & 103 & 3.2310 & & $31.87(26.28-38.67)$ \\
\hline Overweight & 151 & 3.9484 & & $38.24(32.60-44.85)$ \\
\hline Obesity & 83 & 2.1520 & & $38.56(31.10-47.83)$ \\
\hline
\end{tabular}


Table 5: The un-adjusted HR of PN based on the demographic, clinical and Paraclinical characteristics of the studied patients

\begin{tabular}{|c|c|c|}
\hline Components of variable & Hazard ratio & P-value \\
\hline \multicolumn{3}{|l|}{ Residency place } \\
\hline Rural & $0.96(0.75-1.23)$ & 0.788 \\
\hline Urban & 1 & - \\
\hline \multicolumn{3}{|l|}{ Gender } \\
\hline Male & $1.09(0.88-1.35)$ & 0.409 \\
\hline Female & 1 & - \\
\hline \multicolumn{3}{|l|}{ Education } \\
\hline Illiterate & $3.02(1.71-5.32)$ & 0.001 \\
\hline Elementary school (one to five years learning) & $2.64(1.48-4.71)$ & 0.001 \\
\hline Junior school (six to nine years learning) & $2.11(1.12-3.98)$ & 0.021 \\
\hline High school (ten to twelve years learning) & $2.16(1.15-4.03)$ & 0.016 \\
\hline Academic education & 1 & - \\
\hline \multicolumn{3}{|l|}{ Occupation } \\
\hline Governmental & 1 & \\
\hline Retired & $1.95(0.83-4.55)$ & 0.120 \\
\hline Self-employment & $1.50(0.69-3.27)$ & 0.302 \\
\hline Housewife & $1.83(0.86-3.90)$ & 0.116 \\
\hline Unemployed & $2.42(1.11-5.29)$ & 0.026 \\
\hline \multicolumn{3}{|l|}{ Marital status } \\
\hline Married & $3.14(1.86-5.29)$ & 0.001 \\
\hline Single & 1 & \\
\hline Divorced \& Wife died & $5.03(2.87-8.80)$ & 0.001 \\
\hline \multicolumn{3}{|l|}{ Smoking status } \\
\hline Positive & $1.21(0.87-1.68)$ & 0.246 \\
\hline Negative & $\begin{array}{l}1.2(0.07-1.00) \\
1\end{array}$ & - \\
\hline \multicolumn{3}{|l|}{ Physical activity status } \\
\hline Low & 1 & - \\
\hline Moderate & $0.85(0.64-1.13)$ & 0.283 \\
\hline High & $0.86(0.49-1.50)$ & 0.603 \\
\hline Very high & $0.92(0.47-1.78)$ & 0.807 \\
\hline \multicolumn{3}{|l|}{ Blood anti-lipid drugs } \\
\hline No & 1 & - \\
\hline Yes & $1.28(1.03-1.64)$ & 0.034 \\
\hline \multicolumn{3}{|l|}{ Diabetes therapy } \\
\hline Oral medicines & 1 & - \\
\hline Oral medicines and insulin & $1.29(1.02-1.66)$ & 0.036 \\
\hline \multicolumn{3}{|l|}{ Aspirin reception } \\
\hline Yes & $1.43(1.10-1.86)$ & 0.006 \\
\hline No & 1 & \\
\hline Age & $1.025(1.017-1.033)$ & 0.001 \\
\hline BMI & $1.019(0.994-1.044)$ & 0.128 \\
\hline FBS & $1.02(1.01-1.03)$ & 0.001 \\
\hline HBAlc & $1.10(1.04-1.16)$ & 0.001 \\
\hline Cholesterol & $1.002(0.999-1.004)$ & 0.066 \\
\hline LDL & $1.002(0.999-1.005)$ & 0.071 \\
\hline HDL & $0.999(0.989-1.008)$ & 0.871 \\
\hline SBP & $1.014(1.006-1.023)$ & 0.001 \\
\hline DBP & $1.016(1.007-1.026)$ & 0.001 \\
\hline Studying period & $1.16(1.14-1.18)$ & 0.001 \\
\hline
\end{tabular}


Table 6: The adjusted HR of PN based on the demographic, clinical and Paraclinical characteristics of the studied patients

\begin{tabular}{lll}
\hline Components of variable & Hazard ratio & P-value \\
Gender & & \\
Male & $3.66(1.15-11.67)$ & 0.028 \\
Female & 1 & \\
Age & $1.020(1.009-1.06)$ & 0.001 \\
Occupation & & \\
Governmental & 1 & \\
Retired & $1.65(0.69-3.94)$ & 0.254 \\
Self-employment & $1.56(0.71-3.43)$ & 0.268 \\
Housewife & $4.09(1.02-16.38)$ & 0.046 \\
Unemployed & $2.08(0.93-4.67)$ & 0.074 \\
Education & & \\
Illiterate & $1.73(0.94-3.17)$ & 0.076 \\
Elementary school (one to five years learning) & $1.86(1.01-3.47)$ & 0.048 \\
Junior school (six to nine years learning) & $1.90(0.96-3.72)$ & 0.062 \\
High school (ten to twelve years learning) & $2.37(1.22-4.60)$ & 0.011 \\
Academic education & 1 & \\
Marital status & & \\
Single & 1 & 0.001 \\
Married & $2.18(1.24-3.83)$ & 0.007 \\
Divorced \& Wife died & $3.02(1.61-5.65)$ & 0.001 \\
BMI & $1.03(1-1.06)$ & 0.001 \\
Studying period & $1.19(1.17-1.22)$ & \\
\hline & & \\
\hline & & \\
\hline
\end{tabular}

the information was then completed through contacting the patient to provide information on the missing variables. Furthermore, this research study only investigated patients with active medical files in health centers, houses, or diabetes units.

\section{CONCLUSIONS}

The maximum rates of $\mathrm{PN}$ incidence were observed in men, urban patients, and patients with oral medicines and insulin therapeutic regimens, as well as patients who were overweight or obese and those with low physical activity. In addition, the adjusted HR of $\mathrm{PN}$ in men, housewives, divorced or wife died patients, and people with high school education level were higher than the others. Thus, training, screening and diagnostic programs should be conducted with more sensitivity and accuracy in patients who are at greater risk of PN. Furthermore, in order to identify the complications in the initial steps of the disease as well, based on the data in this study, it is advisable to initiate effective and proper therapeutic actions in order to prevent greater complications, and to improve the quality of life in diabetic patients.

\section{ETHICAL CONSIDERATIONS}

This article was extracted from the Ph.D. thesis of Abdollah Mohammadian-Hafshejani from Tehran University of Medical Sciences with the following code: 9221128003. In this study, there was no intervention, nor was any personal information exclusively studied. Furthermore, in order to respect individual privacy, no full names or other private details were included in the checklist of the data collection. All patient information were included in the checklist as codes (including the codes of health centers and patients).

\section{COMPETING INTERESTS}

There are no conflicts of interest.

\section{AUTHORS' CONTRIBUTIONS}

AMH and MAM: initial conception and design of the study. AMH, RM, NM and MAM: critical revision of article. All authors have read and approved the final manuscript. 


\section{FINANCIAL SUPPORT AND SPONSORSHIP}

This study was financially supported by the Deputy of Research and Department of Epidemiology and Biostatistics of Tehran University of Medical Sciences.

\section{ACKNOWLEDGMENTS}

This article is the result of a Ph.D. thesis supported by Tehran University of Medical Sciences. The researchers feel obliged to be grateful to the Research Department of Tehran University of Medical Sciences and Research and Health Departments of Isfahan University of Medical Sciences for supporting the study financially and technically.

\section{ABBREVIATIONS}

BMI: Body mass index

DBP: Diastolic blood pressure

FBS: Fast blood glucose

HBA1c: Glycosylated hemoglobin

HDL: High density lipoprotein

LDL: Low density lipoprotein

PN: Peripheral neuropathy

SBP: Systolic blood pressure

\section{REFERENCES}

1. Otten EJ. Cecil textbook of medicine. The Journal of Emergency Medicine. 2005;28:113-9. Available from: DOI:10.1016/ j.jemermed.2004.10.006.

2. King $H$, Aubert RE, Herman WH. Global burden of diabetes, 1995-2025: prevalence, numerical estimates, and projections. Diabetes Care. 1998;21:1414-31. Available from: DOI:10. 2337/diacare.21.9.1414

3. Morgan CL, McEwan P, Morrissey M, Peters JR, Poole C, Currie CJ. Characterization and comparison of health-related utility in people with diabetes with various single and multiple vascular complications. Diabetic Medicine. 2006;23:1100-5. Available from: DOI:10.1111/j.1464-5491.2006.01936.x.

4. Janghorbani M, Rezvanian $\mathrm{H}$, Kachooei A, Ghorbani A, Chitsaz A, Izadi F. Peripheral neuropathy in type 2 diabetes mellitus in Isfahan, Iran: prevalence and risk factors. Acta Neurologica Scandinavica. 2006;114:384-91. Available from: DOI:10.1111/ j.1600-0404.2006.00716.x.

5. Apfel SC, Asbury AK, Bril V, Burns TM, Campbell JN, Chalk CH, et al. Positive neuropathic sensory symptoms as endpoints in diabetic neuropathy trials. Journal of the Neurological Sciences. 2001;189:3-5. Available from: Doi:10.1016/s0022510x(01)00584-6.

6. Janghorbani M, Rezvanian H, Kachooei A, Ghorbani A, Chitsaz A, Izadi F. Peripheral neuropathy in type 2 diabetes mellitus in Isfahan, Iran: prevalence and risk factors. Acta Neurologica Scandinavica. 2006;114:384-91. Available from: DOI:10.1111/ j.1600-0404.2006.00716.x.

7. Lehtinen JM, Uusitupa M, Siitonen O, Pyorala K. Prevalence of neuropathy in newly diagnosed NIDDM and nondiabetic control subjects. Diabetes. 1989;38:1307-13. Available from: DOI:10.2337/diab.38.10.1307.

8. Dyck PJ, Kratz KM, Karnes JL, Litchy WJ, Klein R, Pach JM. The prevalence by staged severity of various types of diabetic neuropathy, retinopathy, and nephropathy in a population-based cohort: the Rochester Diabetic Neuropathy Study. Neurology. 1993;43:817-24. Available from: Doi:10.1212/wnl.43.4.817.

9. Mueller MJ. Identifying patients with diabetes mellitus who are at risk for lower-extremity complications: use of SemmesWeinstein monofilaments. Physical Therapy. 1996;76:68-71. Available from: DOI:10.1093/ptj/76.1.68.

10. Nitiyanant W, Tandhanand S, Mahtab H, Zhu XX, Pan CY, Raheja BS. The Diabcare-Asia 1998 study-outcomes on control and complications in type 1 and type 2 diabetic patients. Current Medical Research and Opinion. 2002;18:317-27. Available from: Doi:10.1185/030079902125000822.
11. Sobhani S, Asayesh H, Sharifi F, Djalalinia S, Baradaran HR, Arzaghi SM. Prevalence of diabetic peripheral neuropathy in Iran: a systematic review and meta-analysis. Journal of $\mathrm{Di}-$ abetes and Metabolic Disorders. 2014;13:97-107. Available from: DOI:10.1186/s40200-014-0097-y.

12. Tesfaye S, Chaturvedi N, Eaton SE, Ward JD, Manes C, lonescuTirgoviste C. Vascular risk factors and diabetic neuropathy. The New England Journal of Medicine. 2005;352:341-50. Available from: DOI:10.1056/NEJMoa032782.

13. Lloyd CE, Becker D, Ellis D, Orchard TJ. Incidence of complications in insulin-dependent diabetes mellitus: a survival analysis. American Journal of Epidemiology. 1996;143:43141. Available from: DOI:10.1093/oxfordjournals.aje.a008763.

14. Orchard TJ, Forrest KY, Kuller LH, Becker DJ, of Diabetes Complications SPE. Lipid and blood pressure treatment goals for type 1 diabetes: 10-year incidence data from the Pittsburgh Epidemiology of Diabetes Complications Study. Diabetes Care. 2001;24:1053-9. Available from: DOI:10.2337/diacare. 24.6.1053.

15. Lunetta M, Moli RL, Grasso G, Sangiorgio L. A simplified diagnostic test for ambulatory screening of peripheral diabetic neuropathy. Diabetes Research and Clinical Practice. 1998;39:165-72. Available from: Doi:10.1016/s0168-8227(98) 00005-9.

16. Armstrong DG. The 10-g monofilament: the diagnostic divining rod for the diabetic foot? Diabetes Care. 2000;23:887-94. Available from: DOI:10.2337/diacare.23.7.887.

17. Sands ML, Shetterly SM, Franklin GM, Hamman RF. Incidence of distal symmetric (sensory) neuropathy in NIDDM. The San Luis Valley Diabetes Study. Diabetes Care. 1997;20:322-9. Available from: DOI:10.2337/diacare.20.3.322.

18. Booya F, Bandarian F, Larijani B, Pajouhi M, Nooraei M, Lotfi J. Potential risk factors for diabetic neuropathy: a case contro study. BMC Neurology. 2005;5:24-9. Available from: Doi:10. 1186/1471-2377-5-24.

19. Barbosa AP, Medina JL, Ramos EP, Barros HP. Prevalence and risk factors of clinical diabetic polyneuropathy in a Portuguese primary health care population. Diabetes \& Metabolism. 2001:27:496-502.

20. Group DR, The DRG. Factors in development of diabetic neuropathy. Baseline analysis of neuropathy in feasibility phase of Diabetes Control and Complications Trial (DCCT). Diabetes. 1988;37:476-81. Available from: DOI:10.2337/diab.37.4.476.

21. Abbott CA, Malik RA, Ernest RE, Kulkarni J, Boulton AJ. Prevalence and Characteristics of Painful Diabetic Neuropathy in a Large Community-Based Diabetes Population in the UK. Diabetes Care. 2011;p. DC_111108.

22. Khedr EM, Fawi G, Abbas MAA, El-Fetoh NA, Attar GA, Zaki AF. Prevalence of diabetes and diabetic neuropathy in Qena Governorate: population-based survey. Neuroepidemiology. 2016;46:173-81. Available from: Doi:10.1159/000444056.

23. Al-Mahroos F, Al-Roomi K. Diabetic neuropathy, foot ulceration, peripheral vascular disease and potential risk factors among patients with diabetes in Bahrain: a nationwide primary care diabetes clinic-based study. Annals of Saud Medicine. 2007;27:25-31. Available from: Doi:10.4103/02564947.51536.

24. Kuate-Tegueu C, Temfack E, Ngankou S, Doumbe J, Djientcheu VP, Kengne AP. Prevalence and determinants of diabetic polyneuropathy in a sub-Saharan African referral hospital. Journal of the Neurological Sciences. 2015;355:108-12. Available from: DOI:10.1016/j.jns.2015.05.035.

25. Marvasti SK, Abolghasemi J, Heydari I, Rimaz SH. Effective Factors in the Time of Development of Neuropathy in Type II Diabetic Patients. Iranian Journal of Epidemiology. 2017;13:8089.

26. Boru UT, Alp R, Sargin H, Kocer A, Sargin M, Luleci A. Prevalence of peripheral neuropathy in type 2 diabetic patients attending a diabetes center in Turkey. Endocrine Journal. 2004;51:563-7. Available from: DOI: $10.1507 /$ endocrj.51.563.

27. Bennett PJ, Stocks AE, Whittam DJ. Analysis of risk factors for neuropathic foot ulceration in diabetes mellitus. Journal of the American Podiatric Medical Association. 1996;86:112-6. Available from: Doi:10.7547/87507315-86-3-112.

28. Sriussadaporn $S$, Mekanandha $P$ Vannasaeng $S$, Nitiyanant W, Komoltri C, Ploybutr S. Factors associated with diabetic foot ulceration in Thailand: a case-control study. Diabetic Medicine. 1997;14:50-6. Available from: Doi:10.1002/(sici) 1096-9136(199701)14:1<50::aid-dia292>3.0.co;2-6. 
29. Fowler MJ. Microvascular and macrovascular complications of diabetes. Clinical Diabetes. 2008;26:77-82. Available from: DOI:10.2337/diaclin.26.2.77.

30. Hanssen KF, Bangstad HJ, Brinchmann-Hansen O, DahlJorgensen $\mathrm{K}$. Blood glucose control and diabetic microvascular complications: long-term effects of near-normoglycaemia. Diabetic Medicine. 1992;9:697-705. Available from: DOI:10. 1111/j.1464-5491.1992.tb01876.x.

31. Stratton IM, Adler Al, Neil HA, Matthews DR, Manley SE, Cull CA. Association of glycaemia with macrovascular and microvascular complications of type 2 diabetes (UKPDS 35): prospective observational study. BMJ (Clinical Research Ed). 2000;321:405-12. Available from: DOI:10.1136/bmj.321.7258. 405.

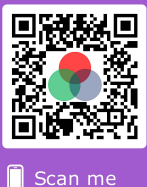

